\title{
A relação entre professores de química e intérprete de libras no curso profissionalizante de uma escola do município de Itumbiara- GO
}

\section{The relationship between chemistry teachers and a pound interpreter in the vocational course of a school in the municipality of Itumbiara - GO}

\author{
${ }^{1}$ Rogério Pacheco Rodrigues rogeriopachecorp@hotmail.com \\ ${ }^{1}$ Fernanda Welter Adams \\ 2 Jaliane Soares Borges dos Santos \\ 3 Jéssyca Lourraine Garcia Eugênio
}

\section{RESUMO}

Com a inclusão, as pessoas surdas e deficientes auditivos passam a ser inseridos no ensino regular, e com isso é necessário a presença de um profissional Tradutor e Intérprete de Libras (TILS) na sala de aula. Entender como estes profissionais estão interagindo com os docentes em sala de aula é de suma importância. Sendo assim, esta pesquisa objetivou realizar um estudo sobre a relação entre professores de química e intérprete de Libras em uma sala de aula inclusiva com o intuito de compreender as implicações e os fatores durante as aulas de química. A pesquisa trata-se de um estudo qualitativo e optou-se pelo uso de questionário contendo 7 (sete) perguntas dissertativas, com a finalidade de traçar o perfil acadêmico dos docentes, bem como informações relacionadas à sua formação, ao ensino de Química na perspectiva inclusiva e a relação entre professor-intérprete no processo de ensino e aprendizagem. Participaram desta pesquisa 3 (três) docentes, sendo um do sexo masculino e duas professoras do sexo feminino, sendo todos com formação em Química. Constatou-se que mesmo com a pouca experiência destes professores com alunos surdos, o trabalho pedagógico entre professor-intérprete é importante, como forma de garantir o processo de ensino e aprendizagem e estes profissionais mostram ter uma boa interação, o que contribui para o ensino da Química, sendo essa uma disciplina de difícil compreensão para os alunos surdos.

Palavras-chave: Inclusão escolar. Docentes. Tradutor e intérprete de libras.

\begin{abstract}
With the inclusion, deaf and hard of hearing people start to be inserted in regular education, and with that it is necessary the presence of a professional Libras Translator and Interpreter (TILS) in the classroom. Understanding how these professionals are interacting with teachers in the classroom is of paramount importance. Therefore, this research aimed to conduct a study on the relationship between chemistry teachers and LIBRAS interpreter in an inclusive classroom in order to understand the implications and factors during chemistry classes. The research is a qualitative study and we opted for the use of a questionnaire containing 7 (seven) essay questions, in order to trace the academic profile of the teachers, as well as information related to their education, to the teaching of Chemistry in the perspective Inclusive and the relationship between teacher-interpreter in the teaching and learning process. Three (3) teachers participated in this research, one male and two female teachers, all of whom have a degree in Chemistry. It was found that even with little experience of these teachers with deaf students, the pedagogical work between teacher-interpreter is extremely important, as a way to guarantee the teaching and learning process and these professionals show to have a good interaction, which contributes to the teaching Chemistry, which is a discipline difficult to understand for deaf students.
\end{abstract}

Keywords: School inclusion. Teachers. Libras translator and interpreter.

1 Instituto Federal de Educação, Ciência e Tecnologia Goiano - Campus Morrinhos

2 Instituto Federal de Educação, Ciência e Tecnologia de Goiás - Campus Itumbiara

3 Escola SENAI unidade de Itumbiara (GO) 


\section{INTRODUÇÃO}

O processo de inclusão de alunos com deficiência na educação regular resultou de uma incessante luta contra preconceitos e discriminações que durante anos se fazem presente em nossa sociedade. Para que o processo educacional voltado às pessoas com deficiência ganhasse o status de inclusão, da forma como hoje conhecemos, três importantes fases no desenvolvimento educacional foram marcantes, são elas: fase de exclusão, fase de segregação institucional e fase de integração (SASSAKI, 1997).

Neste cenário, a política nacional da inclusão escolar na perspectiva da educação inclusiva, enfatiza que todas as instituições de ensino regular têm obrigação de atender e respeitar as necessidades educacionais do aluno incluso na classe regular. Isto é, as escolas devem disponibilizar vários serviços, apoio pedagógico, estratégias e ainda um atendimento educacional especializado (CAMPOS; DUARTE, 2011).

Desse modo compreende-se que a escola deve proporcionar a todos os indivíduos o desenvolvimento social, cognitivo, psicológico e afetivo, de maneira integral, preparando os indivíduos para exercerem suas capacidades e funções de modo pleno na sociedade (NOZI; VITALIANO, 2012).

De acordo com Lacerda (2013) a educação especial inclusiva, especificamente nas escolas regulares de rede pública, vem sendo alvo de grandes desafios e discussões para os profissionais da área, que lutam pela construção do direito à educação para todos. No entanto, as escolas de educação básica recebem alunos surdos e estes têm enfrentado muitos obstáculos em relação à aprendizagem de conceitos científicos.

A educação dos surdos tem se mostrado sempre como um assunto polêmico que requer cada vez mais a atenção de pesquisadores e estudiosos da educação. As propostas educacionais desenvolvidas ao longo do último século não se mostraram eficientes e encontra-se um grande número de sujeitos surdos que após anos de escolarização apresentam uma série de limitações, não sendo capazes de ler e escrever satisfatoriamente e não tendo um domínio adequado dos conteúdos acadêmicos. (LACERDA, 2000, p. 70-71).

Nestas circunstâncias, a educação dos surdos é um cenário desafiador e inspirador. Segundo Tenor e Deliberato (2015), é notório que o processo de inclusão do aluno surdo não depende apenas das ações dos professores em sala de aula, mas da ação de todos os profissionais envolvidos no ambiente escolar

Sabe-se que os surdos possuem sua própria língua predominante, que é a Língua Brasileira de Sinais (LIBRAS) sendo está regulamentada no Brasil por meio da Lei no 10.436 de 24 de abril de 2002 (BRASIL, 2002) e o decreto $n^{\circ} 5.626$ de 22 de Dezembro de 2005 (BRASIL, 2005) que regulamenta, reconhece a língua como uso corrente e legítimo de uma grande parcela dos surdos brasileiros, além de sua inserção e de sua regulamentação nos currículos de Ensino Básico para surdos e nas escolas inclusivas.

A Libras foi instituída como língua oficial da Pessoa Surda (BRASIL, 2006), sendo oficialmente reconhecida no Brasil e definida como:

[...] forma de comunicação e expressão, em que o sistema linguístico[sic] de natureza visual-motora, com estrutura gramatical própria, constituem um sistema linguístico[sic] de transmissão de ideias[sic] e fatos, oriundos de comunidades de pessoas surdas do Brasil (BRASIL, 2002, p. 1).

Para atender as normas do aspecto de educação especial é indispensável a presença de um Tradutor e Intérprete de Libras (TILS) capacitado em sala de aula, cuja atuação reconhecida como profissão pela Lei 12.319 de 1 de setembro de 2010 (BRASIL, 2010). Tal necessidade deve-se ao fato de que o profissional capacitado transmitirá ao surdo as informações orais com fidelidade (DORZIAT; ARAÚJO, 2012). 
O intérprete de Libras é um profissional de apoio que atua diretamente na escola regular, imprescindível na educação das pessoas com surdez. Este profissional é responsável pela tradução/interpretação do conteúdo que é mediado pelo professor ao aluno com esta necessidade específica. Sendo assim, é a pessoa que traduz e interpreta a Língua de Sinais (LS) a língua falada e vice-versa em qualquer modalidade que se apresentar (oral ou escrita) (BRASIL, 2010). Ou seja, a interpretação se refere à atividade de reler uma mensagem de uma dada língua para outra, sem perder o sentido original. Essa atividade envolve: atenção, memória, juízo, raciocínio e imaginação, dentre outros fatores (PEREIRA et al., 2011).

Inúmeros professores não são qualificados para agir diante de um aluno surdo, isto ocorre porque a formação de um licenciado, muitas vezes, não é voltada para a inclusão. E por isto, quando o professor entra em contato com um aluno surdo ocorre o “choque”. Diante disso, é de suma importância, portanto, a presença de um intérprete em sala de aula, pois este é a ponte comunicativa entre o professor e o aluno surdo.

Durante o processo de ensino e aprendizagem do aluno surdo traz aos professores o grande "desafio de se estabelecer uma forma de comunicação efetiva, visto que, uma vez ultrapassada a barreira da aquisição, as demais práticas educativas seriam condizentes com as empreendidas no ensino dos alunos ouvintes” (PEREIRA; MENDES, 2009, p. 43). Para isso conhecer as necessidades educativas específicas da surdez pode auxiliar no processo de ensino e aprendizagem dos surdos.

Com ênfase ao ensino de Química, sabe que esta área é extremamente complexa ao aluno surdo, estes possuem grandes dificuldades na apropriação do conhecimento relacionado à disciplina, e isso ocorre devido à falta de metodologias inovadoras, da ausência de materiais didáticos e da linguagem própria da química, bem como da falta de formação dos professores para lidarem com as especificidades desses alunos.

Nesse sentido, desde 2002, tem-se a Lei no 10.436/02, que reconhece a Libras como meio legal de comunicação e expressão da comunidade surda, determinando que sejam garantidas formas institucionalizadas de apoiar seu uso e difusão, bem como a inclusão da disciplina Libras como parte integrante do currículo nos cursos de formação de professores e de fonoaudiologia. É importante ressaltar que a Libras como disciplina possibilita o desenvolvimento linguístico, social e intelectual de seus usuários, sendo ampliada aos atendimentos públicos da sociedade como um estímulo à inserção dos surdos na sociedade, pois estes poderão exercer sua cidadania de maneira ativa e consciente no âmbito social, em razão de que sua língua será respeitada e reconhecida (ROSSI, 2010).

Jesus (2017) afirma que esta é prevista em lei, e está sendo ministrada pelas instituições públicas que oferecem cursos de licenciatura. Mas, por meio da análise dos Projetos Pedagógicos de Cursos (PPC) e das ementas das Disciplinas Educação Especial e Libras de três cursos de licenciatura ofertados por Instituições de Ensino Superior Públicas, a autora acredita que a contribuição da disciplina Libras no processo de formação inicial do professor é pequena, uma vez que esta desconsidera aspectos importantes e singulares da cultura surda, favorecendo um aprendizado inconsistente e insuficiente para os futuros professores, com lacunas que não foram e não são preenchidas por meio dos conteúdos ministrados e previstos.

Além disto, os profissionais que atuam na interpretação e tradução das aulas de química lidam com a escassez de sinais específicos da química, e isto inibe ainda mais os processos de ensino e de aprendizagem, pois a carência de sinais dificulta a comunicação e a construção do conhecimento do aluno surdo que tem a Libras como língua materna (SALDANHA, 2011).

De acordo com Charallo, Freitas e Zara (2018) um dos principais problemas relacionados ao aprendizado desta disciplina pela maioria dos alunos é o elevado grau de abstração necessário para entender teorias e modelos em nível microscópico e fenômenos observados em escala macroscópica. Esta situação se agrava para alunos surdos na escola inclusiva que tem acesso aos conceitos científicos apresentados pelo professor através de um mediador de Língua de Sinais. 
Nessa perspectiva, esta pesquisa teve como objetivo traçar o perfil de professores de Química que atuam no curso de Auxiliar de Produção de Açúcar e Álcool em uma turma de educação inclusiva na escola do Serviço Nacional de Aprendizagem Industrial (Senai) do município de Itumbiara-Goiás, e identificar a relação professor-intérprete e alguns aspectos que norteiam durante o processo do ensino de química. O curso é ofertado anualmente, e atende demandas de uma Usina Sucroenergética da região e a turma conta com cerca de 20 (vinte) alunos, sendo todos com alguma necessidade específica (visual, auditiva, mental, Física e Múltipla), os quais estão empregados na empresa da região.

No estado de Goiás, o crescimento do setor de produção de açúcar e álcool tem favorecido a expansão do ensino e implantação de cursos em que o foco principal aborda conceitos correlacionados a Química. As discussões sobre as diferentes abordagens dos conteúdos dessa disciplina têm sido cada vez mais recorrentes, enfatizando a necessidade de correlacionar os conceitos com o dia a dia dos estudantes (RIBEIRO; BARRETO, 2012).

\section{METODOLOGIA DA PESQUISA}

O presente trabalho faz referência a uma pesquisa qualitativa. Martins (2004) afirma que a pesquisa qualitativa é importante porque permite coletar evidências a respeito do tema abordado de maneira criadora e intuitiva, visto que há uma proximidade entre pesquisador e pesquisado, possibilitando a compreensão de crenças, tradições, em um máximo entrelaçar com o objeto em estudo. Segundo Zago (2003) uma pesquisa na perspectiva qualitativa deve permitir a compreensão da realidade homogênea do ambiente de estudo. Condição que se articula a percepção apontada anteriormente sobre pesquisador e participante da pesquisa.

A construção dos dados na abordagem qualitativa de uma pesquisa é um momento de suma importância, pois a partir da reflexão dos mesmos a problemática será respondida. Bons dados são construídos a partir de clareza no referencial teórico e seriedade na escolha e construção dos instrumentos a serem utilizados. Segundo Zago (2003) os instrumentos adotados na coleta de dados somente ganham sentido quando articulados à problemática de estudo.

Com relação aos instrumentos, González Rey (2010) afirma que estes representam apenas o meio pelo qual vamos provocar a expressão do participante da pesquisa, ou seja, o instrumento permite que o sujeito se expresse no contexto em que se realiza a pesquisa. Para atingir o objetivo de traçar o perfil de professores de Química que atuam no curso de Auxiliar de Produção de Açúcar e Álcool em uma turma de educação inclusiva na escola do Serviço Nacional de Aprendizagem Industrial (SENAI) do município de Itumbiara-Goiás, inicialmente solicitou-se a autorização da supervisão escolar para a aplicação dos questionários aos professores que atuam diretamente com alunos surdos na escola. Destaca-se a escolha desta instituição de ensino, pois a mesma atende uma turma com 20 (vinte) alunos, os quais todos possuem uma necessidade específica.

Após a autorização, aconteceram as visitas aos professores, conforme data e horário agendados antecipadamente, para explanar sobre os objetivos da pesquisa, bem como, para marcar um horário para a aplicação do questionário e coletar a assinatura no Termo de Compromisso Livre e Esclarecido. Nas datas e horários agendados previamente com cada professor ocorreu a entrega do questionário e estipulou-se o prazo de sete dias para que os mesmos respondessem.

Optou-se pelo uso do questionário como instrumento de coleta de dados, devido à facilidade dos sujeitos responderem as questões no momento em que acharam mais oportuno. Para Gil (1999, p 128-129) os questionários como uma técnica de investigação que por meio de um número mais ou menos elevado de questões escritas, visa "o conhecimento de opiniões, crenças, sentimentos, interesses, expectativas, situações vivenciadas, etc.”. Como vantagens do uso de questionários para a coleta de dados, temos: 
[...] b) Implica menores gastos com pessoal, posto que o questionário não exige o treinamento dos pesquisadores;

c) Garante o anonimato das respostas;

d) Permite que as pessoas o respondam no momento em que julgarem mais conveniente [...]

Os questionários foram compostos por 7 (sete) questões discursivas, que buscavam traçar o perfil acadêmico destes docentes, bem como informações relacionadas à sua formação, ao ensino de Química na perspectiva inclusiva e a relação entre professor-intérprete no processo de ensino e aprendizagem. Os questionários foram respondidos por 3 (três) docentes.

Levando em consideração a ética e o sigilo na identificação dos sujeitos, os mesmos foram identificados como: P1, P2 e P3. Todos os professores ministram aulas do componente curricular de Química no curso de Auxiliar de Produção de Açúcar e Álcool.

\section{RESULTADOS E DISCUSSÃO}

Historicamente os alunos público alvo da educação especial são diferenciados daqueles alunos ditos então “normais”, mas vemos movimentos políticos na década de 1990 que buscam superar essa segregação e então garantir o acesso e permeância destes sujeitos na escola regular. Segundo Turqueti et al., (2013) as políticas públicas em educação devem promover o acesso e permanência de todos, mas não apenas no que concerne à sua presença física. Trata-se de acesso e permanência com qualidade, o que implica serviços educacionais adequados.

Enfim, a garantia da presença do aluno já foi conquista na atualidade lutamos pela garantia do direito do desenvolvimento cognitivo deste aluno. Corroborando com essa ideia, Turqueti et al., (2013), além de trazer muitos desafios nos âmbitos legais, a prática de educação inclusiva envolve tomada de decisões e desenvolvimento de ações que deverão levar em conta não só a garantia de direitos como também um ensino de qualidade que possa realmente beneficiar a todos, independentemente de suas necessidades. Os princípios de inclusão e qualidade são complementares, não excludentes. Sendo então a formação de professores um dos aspectos centrais para a garantia da inclusão e do processo de ensino e aprendizagem dos alunos com deficiência.

Dessa forma, levantou-se o perfil dos sujeitos participantes, que se descreve o no quadro 1. Por meio desse perfil, foi possível observar que os professores possuem pouca experiência no que diz respeito à atuação com os alunos surdos, experiência essa que ocorreu, devido ao programa "Veja Diferente” ter sido implantado em 2016 na escola.

\section{Quadro 1 - Perfil dos Professores de Química}

\begin{tabular}{|l|l|l|l|l|l|}
\hline Professor & Sexo & Idade & Formação Acadêmica & $\begin{array}{l}\text { Profissão como } \\
\text { Docente }\end{array}$ & $\begin{array}{l}\text { Experiência com } \\
\text { Alunos Surdos }\end{array}$ \\
\hline P1 & M & 27 anos & $\begin{array}{l}\text { Técnico em Química e } \\
\text { Bacharelado em Farmácia }\end{array}$ & 4 anos & 2 anos \\
\hline P2 & F & $\begin{array}{l}\text { Licenciatura em Química, } \\
\text { especialização em Docência } \\
\text { na Educação Profissional e } \\
\text { Tecnológica Mestrado em } \\
\text { Defesa Sanitária Vegetal. }\end{array}$ & 8 anos & 2 anos \\
\hline P3 & F & $\begin{array}{l}\text { Licenciatura em Química e } \\
\text { Especialização em Docência } \\
\text { na Educação Profissional e } \\
\text { Tecnológica }\end{array}$ & 8 anos & 1 ano \\
\hline
\end{tabular}

Fonte: produção própria, a partir das respostas dos questionários respondidos pelos sujeitos (2019). 
Por meio do tempo de profissão docente, acredita-se que os sujeitos devem ter vivenciado a inclusão da disciplina Libras nos cursos de graduação, por meio do o Decreto $n^{0}$ 5.626/05, que afirma que todos os cursos de formação de professores devem inserir em seus currículos a disciplina de Libras a qual tem como objetivo formar os professores que serão responsáveis pelo ensino dos alunos surdos nas escolas inclusivas, sendo ela a única disciplina específica desta área no currículo de formação. Mas, acredita-se que apenas a inserção desta disciplina não é garantia dos licenciandos uma formação consolidada na área da educação especial.

A partir da pouca experiência dos professores com os alunos surdos se faz de extrema importância que estes trabalhassem em colaboração com o intérprete de Libras de forma a garantir o processo de ensino e aprendizagem do aluno, nessa perspectiva temos o excerto de P2:

Excerto 1 - Todo o material é passado com antecedência para o intérprete, facilitando assim o processo de Tradução e Interpretação das aulas.

Por meio da fala de P2 vemos que esse trabalho em colaboração vem acontecendo entre o professor e o intérprete. Uma vez, que se acredita que, para promover a educação especial não basta somente que o aluno surdo frequente uma sala de aula, mas faz-se necessário que suas especificidades sejam atendidas, de forma a garantir o desenvolvimento cognitivo do mesmo.

No entanto, destaca-se o papel do professor, quanto ao desenvolvimento de um trabalho que valorize todas as diferenças, e que está valorização esteja pautada nos objetivos de uma educação, que vise a valorização do exercício e cidadania, e a preparação para estar inserido nos mais variados contextos sociais. E para tanto, se faz necessário à interação do aluno surdo com o ouvinte.

Excerto 2 - "Apesar de todas as limitações temos um aprendizado homogêneo e todos os alunos se preocupam em comunicar com os surdos". (P1)

Excerto 3 - "Eles têm uma boa interação, muitos alunos até aprenderam alguns sinais para se comunicar com os alunos surdos" (P2)

Percebemos nas falas de P1 e P2 que os demais alunos buscam essa comunicação, o que também contribui com o processo de ensino e aprendizagem do aluno, uma vez que a socialização é importante para o desenvolvimento de diversas habilidades, ou seja, o aluno se insere em um grupo cultural e social, e o aprendizado ocorre mediante a inserção do indivíduo em um grupo cultural, promovendo assim o desenvolvimento cognitivo do mesmo.

Adams (2018) corrobora com essa afirmação dizendo que quando o aluno começa a dominar conhecimentos de química, passa a ser transformado não só pelo conteúdo das disciplinas que lhe oferecem outra base explicativa dos eventos, dos fatos, mas também é provocado a ter um modo de pensar mais complexo, a dirigir voluntariamente sua atenção, a lembrar-se das coisas de modo mediado. Neste sentido, a escolarização provoca verdadeiras revoluções nos alunos.

Mas essa interação também precisa ser mediada, de forma que os alunos tenham contato com os diversos grupos da sala:

Excerto 4 - "Pela experiência que tive, percebi que inicialmente o professor tem que mediar a interação, caso contrário os grupos são formados por pessoas com deficiências semelhantes” (P3)

Portanto, a mediação é fundamental para o desenvolvimento do aluno surdo. Os conhecimentos já elaborados pelos homens devem mediados pelo professor aos estudantes através de um planejamento que leve em consideração as potencialidades dos alunos com deficiência o que permite que os mesmos tenham acesso ao desenvolvimento cultural (ADAMS, 2018). Portanto, acredita-se que o bom aprendizado ocorre por meio da mediação. E essa mediação é importante tanto para o desenvolvimento cognitivo como para o desenvolvimento social. 


\section{CONCLUSÃO}

Ao analisar os dados obtidos pode-se observar que na escola Senai de Itumbiara-Go acorre uma boa interação entre professor e intérprete de Libras, o que contribui para o ensino e aprendizagem de Química, sendo essa uma disciplina de difícil compreensão para os alunos surdos.

Notamos que os professores já possuem a iniciativa de encaminhar o material para o intérprete com antecedência, para assim realizar a adaptação de material, e também trabalham o conteúdo utilizando imagens, para assim melhorar o processo de ensino do aluno surdo. No entanto, também é pertinente que o docente utilize metodologias, estratégias de ensino que atendam as especificidades dos alunos surdos.

\section{REFERÊNCIAS}

ADAMS, F. W. Docência, Formação de Professores e Educação Especial nos Cursos de Ciências da Natureza. Dissertação (Mestrado) - Universidade Federal de Goiás, Unidade Acadêmica Especial e Educação - Programa de Pós-Graduação em Educação, Catalão, 2018.

BOTELHO, P. Educação inclusiva para surdos: desmistificando pressupostos. Sociedade Inclusiva. M.G., 1999.

BRASIL. Decreto no 5.626. Regulamenta a Lei no 10.436, de 24 de abril de 2002, e o art. 18 da Lei $n^{\circ} 10.098$, de 19 de dezembro de 2000. Publicado no diário Oficial da União em 22 de dezembro de 2005.

. Lei no 10.436. Dispõe sobre a Língua Brasileira de Sinais - LIBRAS e dá outras providências. Publicado no diário Oficial da União em 24 de abril de 2002.

Língua Brasileira de Sinais: “uma conquista histórica”. Senado Federal: Brasília, 2006.

Lei n. 12.319/10, 1 de setembro de 2010. Reconhece a profissão do Tradutor e Intérprete de Língua de Sinais. Diário Oficial da República Federativa do Brasil, Brasília, DF.

CAMPOS, J. A. P. P.; DUARTE, M. O aluno com deficiência na EJA: reflexões sobre o atendimento educacional especializado a partir do relato de uma professora. Revista Educação Especial, v. 24, n. 40, p. 271-284, 2011.

CHARALlO, T. G. C.; FREITAS, K. R.; ZARA, R. A. Análise dos Sinais de Química Existentes em Libras Segundo a Gestualidade. Experiências em Ensino de Ciências, v.13, n.1, 2018.

DORZIAT, A.; ARAÚJO, J. R. O intérprete de língua de sinais no contexto da educação. Revista Brasileira de Educação Especial, v. 18, n. 3, p. 391-410, 2012.

GIL, A. C. Métodos e técnicas de pesquisa social. 5ª edição. São Paulo: Atlas, 1999.

GONZÁLEZ REY, F. L. Pesquisa Qualitativa e Subjetividade: os processos de construção da informação. Tradução Marcel Aristides Ferrada Silva. São Paulo: Cengage Learning, 2010.

JESUS, L. F. Formação Inicial De Professores: Contribuição da Disciplina Libras para Futuros Professores da Educação Básica. 2017. Dissertação (Mestrado Profissional em Ensino Tecnológico) - Programa de Pós Graduação do Instituto Federal de Educação, Ciência e Tecnologia do Amazonas, 2017.

LACERDA, C. B. F. de. A prática pedagógica mediada pela língua de sinais: trabalhando com sujeitos surdos.

Caderno CEDES, Campinas, v. 20, n. 50, 2000. 
LACERDA, C. B. F.; SANTOS, L. F. Tenho um aluno surdo, e agora? Introdução à libras e educação de surdos. 1. ed. São Carlos: EDUFSCar, 2013. v. 1, 254p.

MARTINS, H. H. T. D. Metodologia qualitativa de pesquisa. Educação e Pesquisa, São Paulo, v.30, n.2, p. 289-300, 2004.

NOZI, G. S.; VITALIANO, C. R. Saberes necessários aos professores para promover a inclusão de alunos com necessidades Educacionais Especiais. Revista Educação Especial, v. 25, n. 43, p. 333 - 348, 2012.

PEREIRA, V. A.; MENDES, E. G. Análise conceitual da deficiência auditiva: perspectivas históricas e educacionais. In: da COSTA, M. P. R. (Org). Educação Especial: aspectos conceituais e emergentes. São Carlos: EDUFSCar, 2009.

PEREIRA, L. L. S.; BENITE, C. R. M.; BENITE, A. M. C. Aula de Química e Surdez: sobre Intervenções Pedagógicas Mediadas pela Visão. Química Nova na Escola, v. 33, n. 01, 2011.

RIBEIRO, R. N.; BARRETO, S. O papel do professor no processo de ensino - aprendizagem de química na educação para jovens e adultos (EJA). In:Encontro Nacional de Ensino de Química, 16. 2012, Salvador. Anais...Salvador: Eneq, 2012.

ROSSI, R. A. A Libras como disciplina no Ensino Superior. Revista de Educação, v. 13, n. 15, p. 71-85, 2010.

SALDANHA, J. C. O ensino de química em língua brasileira de sinais. 2011. 160f. Dissertação (Mestrado em Ensino das Ciências na Educação Básica) - Curso de Pós Graduação Pós Graduação em Ensino das Ciências na Educação Básica, Universidade do Grande Rio Universidade “Prof. José de Souza Herdy”, Duque de Caxias, 2011.

SASSAKI, R. K. Inclusão: construindo uma sociedade para todos. 8. ed. Rio de Janeiro: WVA, 1997.

TENOR, A. C.; DELIBERATO, D. Sistematização de um programa de capacitação ao professor do aluno surdo. Revista Brasileira de Educação Especial, v. 21, n. 3, p.409-422, 2015.

TURQUETI, A.; SOUZA, C. B. G.; CHINALIA, F. Formação de professores na perspectiva da educação inclusiva: considerações iniciais sobre as políticas educacionais. In: MARTINS, S. E. S. O.; GIROTO, C. R.; SOUZA, C. B. G. (org.) Diferentes olhares sobre a inclusão São Paulo: Cultura Acadêmica; Marília: Oficina Universitária, 2013.

ZAGO, Nadir et all. (Org.). Itinerários de Pesquisa - perspectivas qualitativas em Sociologia da Educação. Rio de Janeiro: DP\&A, 2003. 